\title{
Bubble Columns Staged with Structured Fibrous Catalytic Layers: Residence Time Distribution and Mass Transfer
}

\author{
Volker Holler, Kajsa Radevik, Lioubov Kiwi-Minsker, and Albert Renken*
}

Swiss Federal Institute of Technology (EPFL) CH-1015 Lausanne, Switzerland

\begin{abstract}
A new reactor concept for catalyzed three-phase reactions based on the use of woven fibrous materials for bubble columns is suggested. In comparison to conventional multistage bubble columns, the trays are made from woven fibrous catalytic layers. The hydrodynamic parameters such as the residence time distribution (RTD) and the volumetric gas-liquid mass transfer coefficient $\mathrm{k}_{\mathrm{L}} \mathrm{a}$ are investigated in an air/water system for different layer structures and different superficial gas $\left(u_{g 0}<60 \mathrm{~cm} / \mathrm{s}\right)$ and liquid $\left(u_{10}<6 \mathrm{~cm} / \mathrm{s}\right)$ velocities. The major reactor design parameters, such as the thread diameter $\mathrm{D}$, the distance between the woven threads $\mathrm{w}$, and the distance between the fibrous layers $b$, are discussed.
\end{abstract}

\section{Introduction}

In the conventional gas-liquid-solid bubble columns, the solid phase is usually present in the form of pellets in a randomly packed bed or in the form of fine powder suspended in the liquid phase. Both column designs have some disadvantages, such as bubble coalescence, low gas-liquid mass transfer, liquid back-mixing, and the problem of fine powder filtration. ${ }^{1-4}$ Recently, we suggested a new three-phase reactor concept using fibrous structured catalysts for the design of staged bubble columns. ${ }^{5-7}$ In comparison with conventional multistage cascade bubble col umns, the trays are made from fibrous supported catalysts. Two main zones can be distinguished in this reactor: the bubble zone and the reaction zone (Figure 1 ). In the bubble zone, the gas and liquid phases are mixed intensively in the axial and radial directions, leading to the saturation of the liquid phase by the gas. In the reaction zone, gaseous and liquid reactants interact with the fibrous catalyst.

A spatial separation of these two zones gives following advantages: reduced axial mixing because of the horizontally placed fabric layers, ${ }^{8,9}$ enhanced mass transfer performance by the repeated redistribution of the gas phase,, 89 controlled liquid saturation by the gas because of the sizing of the bubblezones, and reaction conversion control by the amount of catalyst as a function of the reactor length.

To overcome the separation problem common for suspended-bed reactors, bubble columns with packed beds are proposed. The larger diffusion length al ong the catalyst pellet compared to the powder might lead to reaction kinetics limited by diffusion and, consequently, to a decrease in the catalyst efficiency and eventually in the product selectivity. In contrast to packed bubble columns, where a minimum pell et diameter is given by a maximal tolerable pressure drop, fibrous catalysts

* Author to whom correspondence should be addressed. Phone: +41-21-693 3181. Fax: +41-21-693 3190. E-mail: al bert.renken@epfl.ch.

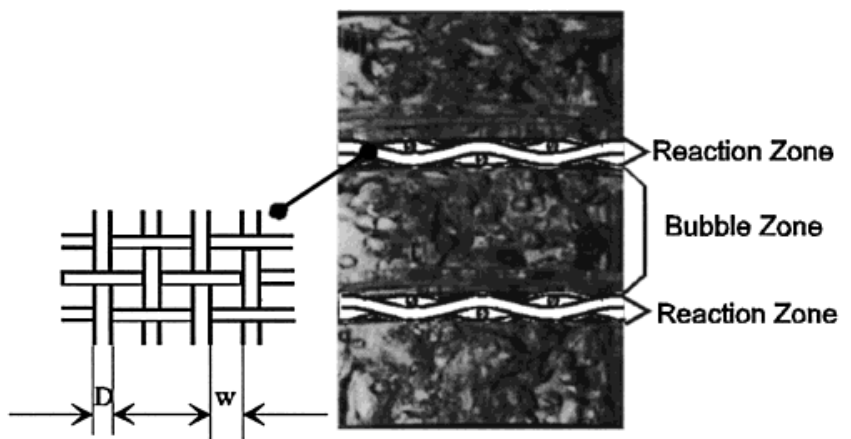

Figure 1. Bubble column staged with structured fibrous catalysts.

offer the possibility of short diffusion lengths because of their open macrostructures.

In our previous publications, ${ }^{5,7}$ several hydrodynamic parameters of the staged bubble column, such as the liquid hold-up and the pressure drop through the bed, were investigated and described by empirical equations. The present work aims at investigating the hydrodynamics of the reactor without any chemical reaction to understand the influence of the fabric structure on the flow parameters. Therefore, the residence time distribution (RTD) of the liquid phase and the gas-liquid mass transfer are determined. The geometrical parameters of the bubble columns staged with structured glass fiber catalysts are subsequently discussed.

\section{Experimental Section}

2.1. Fibrous Layers. Woven fabrics made of E-type glass (EGF) were used as a prototype of fibrous supports for hydrodynamic studies in the structured bed. The fabrics were woven from threads with a diameter $D$ consisting of a bundle of elementary filaments with a diameter $\mathrm{d}$ of 3-10 $\mu \mathrm{m}$. The main characteristic dimensions of the fabrics used in this study are summarized in Table 1. Detailed information is reported el sewhere. ${ }^{7}$

2.2. Experimental Setup and Procedure. Residence Time Distribution. An acrylic glass column with 
Table 1. Fabric Structural Parameters

\begin{tabular}{cccc}
\hline fabric & $\begin{array}{c}\text { thread diameter D } \\
(\mathrm{mm})\end{array}$ & $\begin{array}{c}\text { thread distance w } \\
(\mathrm{mm})\end{array}$ & $\begin{array}{c}\text { open area } \mathrm{A}_{0} \\
(\%)\end{array}$ \\
\hline $\mathrm{f}-\mathrm{w} 0.3$ & 0.3 & 0.3 & 25 \\
$\mathrm{f}-\mathrm{w} 0.6$ & 0.7 & 0.6 & 25 \\
$\mathrm{f}-\mathrm{w} 1.3$ & 2.4 & 1.3 & 15
\end{tabular}

an inner diameter of $24 \mathrm{~mm}$ was staged with woven fibrous supports. ${ }^{7}$ The residence time distribution (RTD) was measured via two conductivity cells installed at the top and at the bottom of the column with a distance of $180 \mathrm{~mm}$ between them. Each cell was constructed from two parallel circular copper gauzes, as suggested by Gelder et al.,10 allowing for the determination of the liquid conductivity over the entire column section (volume-averaged measurements). Briens et al. ${ }^{11}$ showed that, in the case of strong back-mixing, which is common for empty bubble columns, the use of volume-averaged measurements gives an incorrect determination of the RTD. Because in our study no backflow occurs through the conductivity cells (tanks-in-series model), the determination of the RTD is correct. As a tracer, a solution of potassium chloride $(0.3 \mathrm{~mL}, 10 \mathrm{wt} \% \mathrm{KCl})$ was used, and the inlet and outlet responses were registered at $0.1 \mathrm{~s}$ intervals. The experimental data were smoothed with a moving average filter (5-point filter for the inlet, 9-point filter for the reactor outlet). ${ }^{12}$

The mean residence time $\bar{t}$ and the variance $\sigma^{2}$ of the residence time distribution are given by the first and second central moments of the response curves. ${ }^{13}$ The dimensionless variance $\sigma_{\theta}{ }^{2}$ is calculated as

$$
\sigma_{\theta}^{2}=\frac{\sigma^{2}}{\overline{\mathrm{t}}^{2}}=\frac{\sigma_{\text {out }}{ }^{2}-\sigma_{\text {in }}{ }^{2}}{\left(\overline{\mathrm{t}}_{\text {out }}-\overline{\mathrm{t}}_{\text {in }}\right)^{2}}
$$

Because the distance between the fabrics $b$ has an influence on the flow pattern, ${ }^{7}$ it was varied among 60 $\mathrm{mm}$ ( 2 fabrics in the column), $30 \mathrm{~mm}$ (6 fabrics), and $15 \mathrm{~mm}$ (12 fabrics).

Gas-Liquid Mass Transfer. Gas-liquid mass transfer rates were determined by desorption of oxygen from saturated water by a nitrogen sweep-flow and characterized via the volumetric gas-liquid mass transfer coefficient, $\mathrm{k}_{\mathrm{L}} \mathrm{a}$. The experimental setup is shown in Figure 2. The acrylic glass column staged with three fibrous supports was used as the bubble column. Water and $\mathrm{N}_{2}$ flowed cocurrently upward; the feeds were controlled by flow meters (Vögtlin, Switzerland). The oxygen concentration was determined with an $\mathrm{O}_{2}$ sensor (Bioengineering $A G$ ).

Assuming plug-flow behavior in the reactor, the average volumetric mass transfer coefficient $\mathrm{k}_{\mathrm{L}} \mathrm{a}$ can be directly calculated form the measured oxygen concentration via

$$
\mathrm{k}_{\mathrm{L}} \mathrm{a}=\frac{1}{\overline{\mathrm{t}}} \ln \frac{\mathrm{C}_{\text {in }}-\mathrm{c}_{\text {equ }}}{\mathrm{c}_{\text {out }}-\mathrm{C}_{\text {equ }}}
$$

where $\mathrm{k}_{\mathrm{L}} \mathrm{a}$ is the volumetric mass transfer coefficient; $c_{i n}$ and $c_{\text {out }}$ are the dissolved oxygen concentrations at the reactor inlet and outlet, respectively; and cequ is the oxygen liquid-phase concentration at the gas-liquid interface. Because of the relatively high gas flow, the oxygen concentration in the gas phase is negligible. Assuming that the main transport resistance is in the liquid phase, cequ can also be assumed to be zero.
The gas-liquid mass transfer takes place in the column section and in the outlet section. To calculate the $k_{L} a$ value of the column section, the gas-liquid mass tansfer rate was determined for the outlet section (Figure 2A) and for the entire column (Figure 2B). Assuming an identical mass transfer coefficient for the outlet section in setup A and setup B under the same experimental conditions, the volumetric mass transfer coefficient $\left(k_{L} a\right)_{c o l u m n}$ of the column section can be calculated as

$$
\left(\mathrm{k}_{\mathrm{L}} \mathrm{a}\right)_{\text {column }}=\frac{1}{\overline{\mathrm{t}}_{\text {column }}} \ln \frac{\mathrm{C}_{\mathrm{A}}}{\mathrm{C}_{\mathrm{B}}}
$$

where $\bar{t}_{\text {column }}$ is the residence time in the column section and $C_{A}$ and $C_{B}$ are the $\mathrm{O}_{2}$ concentrations in the liquid phase in the separator for experimental runs $A$ and $B$, respectively.

\section{Results and Discussion}

3.1. Residence Time Distribution. Mean Residence Time $\overline{\mathrm{t}}$ and Dimensionless Variance $\sigma_{\mathrm{t}}{ }^{2}$. In Figure 3, typical response curves $\mathrm{C}(\mathrm{t})$ at the inlet and outlet sections for a tracer injection are shown. Conductivity measurements in a small volume are known to be influenced by gas-liquid flows. A significant reduction in the measured conductivity occurs when a bubble contacts the probe. In our study, only small fluctuations in the response curves $\mathrm{C}(\mathrm{t})$ were observed, as the conductivity was measured over the entire column cross section. ${ }^{14}$

In Figure 4, the mean residence time $\overline{\mathrm{t}}$ is plotted versus the superficial liquid velocity $u_{10}$. An approximately $20-35 \%$ higher liquid mean residence time $\bar{t}$ of a reactor staged with layers of fabric $\mathrm{f}$-w1.3 compared to a reactor staged with fabrics $\mathrm{f}-\mathrm{w} 0.3$ can be seen. As described in our previous publication, ${ }^{7}$ gas pads are formed bel ow each fabric layer. Decreasing the distance between the threads $w$ leads to a higher pressure drop $\Delta \mathrm{p}_{\mathrm{f}}$, to a larger gas pad under each fabric layer, and therefore, to a lower residence time $\bar{t}$.

The residence time distribution can be characterized by the variance around the mean. In Figure 5, the dimensionless variance $\sigma_{\theta}{ }^{2}$ is plotted as a function of the liquid superficial velocity $u_{10}$ for a reactor with different numbers of stages. For an empty column or a column with only two stages, a dependence of the dimensionless variance $\sigma_{\theta}{ }^{2}$ on the liquid flow is observed. For large distances between the stages, "slug and churn flow" patterns were observed, ${ }^{7}$ which are characterized by large bubbles moving with high rise velocities in the presence of small bubbles ${ }^{1}$ and a chaotic up/down motion of the liquid phase. An increase of the liquid velocity $u_{10}$ changes the flow pattern from slug/ churn flow to the bubble-flow regime, where the gas is dispersed in small bubbles with a narrow size distribution. The large bubbles in the slug/churn regime lead to a nonideal mixing of the liquid phase, in contrast to the higher amount of small bubbles in bubble-flow regime. F or a reactor staged with 6 and 12 fabric layers, the variance $\sigma_{\theta}{ }^{2}$ was found to be independent of the liquid velocity $u_{10}$, the superficial gas velocity $u_{g 0}$, and the fabric layer structure.

Tanks-in-Series Reactor Model. The tanks-in-series model ${ }^{13}$ is used to describe the residence time distribution of the liquid phase in the studied bubble column 

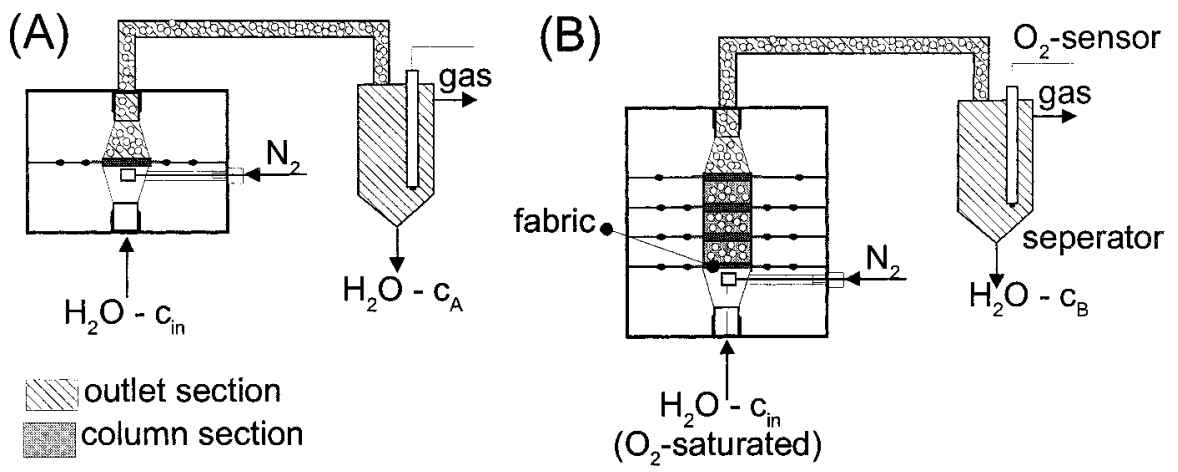

Figure 2. Experimental setup for the determination of the volumetric mass transfer coefficient $k_{L} a$.

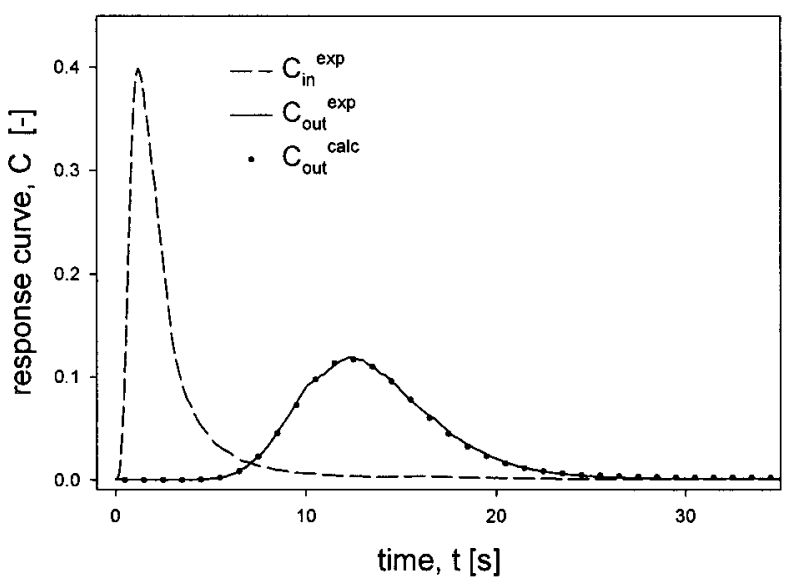

Figure 3. Response curves $C$ for a reactor staged with $12 \mathrm{GF}$ layers (f-w0.3, $\mathrm{u}_{\mathrm{g} 0}=6.1 \mathrm{~cm} / \mathrm{s}, \mathrm{u}_{10}=0.61 \mathrm{~cm} / \mathrm{s}, \mathrm{N}=13, \overline{\mathrm{t}}=10.9 \mathrm{~s}$ ).



Figure 4. Mean residence time $\bar{t}$ versus liquid superficial velocity $\mathrm{u}_{10}$ for a reactor staged with 12 fibrous layers (f-w0.3).

reactor. The age distribution $\mathrm{E}(\mathrm{t})$ for $\mathrm{N}$ perfectly mixed tanks in series can be calculated as a function of the mean residence time $\bar{t}$ and the number of tanks $N$.

$$
E(t)=\frac{1}{\bar{t}} \frac{N(N t / \bar{t})^{N-1}}{(N-1) !} e^{-N t / \bar{t}}
$$

With the convolution integral of eq 5 , the number of tanks $\mathrm{N}$ and the mean residence time $\overline{\mathrm{t}}$ were determined by fitting the calculated output signal $\mathrm{C}_{\text {out }}^{\text {calc }}(\mathrm{t})$ to the measured output response signal $\mathrm{C}_{\text {out }}^{\exp }(\mathrm{t})$. The calculated values are in a remarkably good agreement with the measured data, as shown in Figure 3.



Figure 5. Dimensionless variance $\sigma_{\theta}{ }^{2}$ versus superficial liquid velocity $u_{10}$ for the reactor packed with 12,6 , and 2 GF fabric layers or without any packing.

$$
C_{\text {out }}^{\text {calc }}\left(t_{i}\right)=\sum_{0}^{t_{i}} C_{\text {in }}^{\text {exp }}\left(t_{j}\right) E\left(t_{i}-t_{j}\right) \Delta t
$$

In Figure 6, the calculated number $\mathrm{N}$ of ideal mixed tanks is pl otted versus the superficial liquid vel ocity $u_{10}$ as a function of the number of physical stages $\mathrm{S}$ in the reactor, the fiber structure, and the superficial gas velocity $u_{g 0}$. It was experimentally found that, because of the presence of the conductivity cells, the number of stages is equal to the number of fabric layers plus one. For three stages (two fabrics), the increase in the calculated tanks $\mathrm{N}$ with the liquid superficial velocity $u_{10}$ is due to the change of the flow pattern (see above). In a column with six or more fabrics, the number of tanks $\mathrm{N}$ corresponds to the number of stages $\mathrm{S}$. This implies a perfect axial mixing between the fabric layers but noliquid backflow between neighboring stages. This effect was observed in our study for cross-sectional areas $A_{0}$ up to $25 \%(I D=24 \mathrm{~mm})$. Blass et al. ${ }^{15-17}$ reported the same hydrodynamics in a bubble column staged with perforated plates of a lower cross-sectional area $\left(A_{0}=4.4 \%\right)$ and a larger ID of $140 \mathrm{~mm}$. Therefore, we suppose that the backflow does not depend on the column diameter.

In contrast to our results, those authors ${ }^{15-17}$ found a dependency of the axial mixing on the liquid and gas throughput for high cross-sectional areas $A_{0}$. These different results might be caused by the smaller openings of the fibrous layers $(\mathrm{w}=0.3-1.3 \mathrm{~mm})$ compared to the large hole diameters of the perforated plates (hole diameter $=4 \mathrm{~mm}$ ). For technical applications of the bubble columns staged with fibrous catalysts in which the number of stages $S$ will be larger than seven, resulting in a dimensionless fabric distance b/I D smaller 


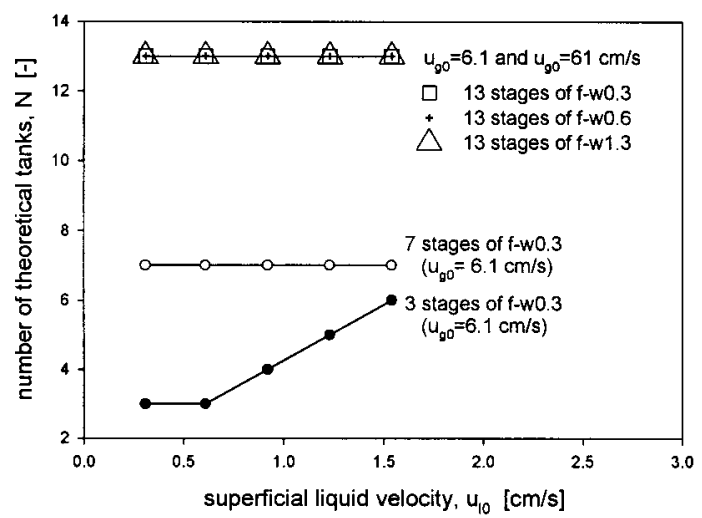

Figure 6. Number of perfectly mixed tanks $\mathrm{N}$ versus the superficial liquid velocity $u_{10}$.



Figure 7. Volumetric gas-liquid mass transfer coefficient $\mathrm{k}_{\mathrm{L} a}$ versus superficial gas velocity $u_{g o}$ for different GF fabrics and different superficial liquid velocities $u_{10}$.

than unity, the independence of back-mixing on the superficial gas and the superficial liquid velocities provides an important degree of freedom for the reactor design.

3.2. Volumetric Gas-Liquid Mass Transfer. Figure 7 shows the volumetric mass transfer coefficient $k_{\mathrm{L}} a$ as a function of the superficial gas velocity for the fabric layers f-w0.3, f-w0.6, and f-w1.3. The maximum $\mathrm{O}_{2}$ mole fraction in the gas phase was $0.5 \%$, leading to a negligible liquid-phase concentration $c_{\text {equ }}$ at the interface (in all experiments, $C_{\text {equ }} / C_{B}$ was smaller than $1 \%$ ). The deviation of the liquid concentrations $C_{A}$ and $C_{B}$ because of the nonideal plug-flow behavior can be calculated for $\mathrm{N}$ tanks in series with eq $6 .{ }^{13}$

$$
\frac{\mathrm{C}_{\mathrm{N} \text { tanks }}}{\mathrm{C}_{\text {plug-flow }}}=1+\frac{\left(\mathrm{k}_{\mathrm{L}} \mathrm{a} \overline{\mathrm{t}}\right)^{2}}{2 \mathrm{~N}}
$$

Incorporating eq 6 into eq 3 under the assumption that $\mathrm{N}$ is 3 shows that the determined $\mathrm{k}_{\mathrm{L}} \mathrm{a}$ values were underestimated (average 10\%, maximum 17\%). A determination of the $k_{L} a$ value at superficial gas vel ocities higher than $6.2 \mathrm{~cm} / \mathrm{s}$ was not possible, as the rapid gasliquid mass transfer leads to an $\mathrm{O}_{2}$ concentration in the water that is at the detection limit. ${ }^{2}$

The $k_{\mathrm{L} a}$ coefficient increases not only with the gas flow rate, but also with the liquid flow rate, which is in accordance with results. $8,9,18,19$ This is an advantage of staged bubble columns, as it is known that, in empty columns, the liquid flow shows a negligible effect on the $k_{L} a$ value. An influence of the fabric layer structure on

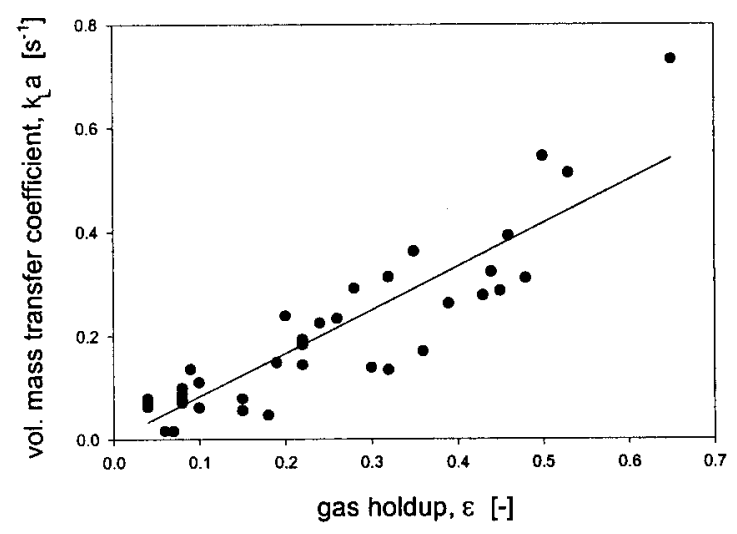

Figure 8. Volumetric mass transfer coefficient $k_{L} a$ as a function of the total gas holdup $\epsilon$ ( $\epsilon$ values from ref 7).

the $k_{\mathrm{L}} \mathrm{a}$ value was observed for a small distance between the threads $w(w<0.6 \mathrm{~mm})$. The higher gas-liquid mass transfer for fabric $\mathrm{f}$-w0.3 is due to a more favorable gas distribution by the dense layers. Because the better gas distribution was only observed for superficial gas velocities lower than $15 \mathrm{~cm} / \mathrm{s}$, an independence of the $\mathrm{k}_{\mathrm{L}} \mathrm{a}$ values from the fabric structure for larger superficial gas velocities can be expected.

Chen et al. ${ }^{8}$ found similar $k_{\mathrm{L}}$ a values for various column diameters, varied from 51 to $150 \mathrm{~mm}$, in a multistage bubble col umn equipped with screen plates. Therefore, the influence of the column diameter on the $\mathrm{K}_{\mathrm{L}} \mathrm{a}$ values can be neglected.

A comparison of the $k_{\mathrm{L}} a$ values determined for the staged bubble column with the values for an empty bubble column 20,21 in Figure 7 shows a significantly higher mass transfer rate. The $\mathrm{k}_{\mathrm{L}} \mathrm{a}$ in a column staged with fabric $\mathrm{f}$-w0. 3 is about 10 times higher than that in the conventional bubble column. The increased $\mathrm{k}_{\mathrm{L}} \mathrm{a}$ values are due to the higher gas holdup and the small size of bubbles.

In Figure 8, the gas-liquid mass transfer coefficient $\mathrm{k}_{\mathrm{L}} \mathrm{a}$ is plotted as a function of the overall gas holdup $\epsilon$. The ratio between the volumetric gas-liquid mass transfer coefficient and the gas holdup is constant $\left(k_{\llcorner} a\right)$ $\cong 0.8 \mathrm{~s}^{-1}$ ). Vermeer and Krishna 22 and Letzel et al. ${ }^{20}$ found a ratio of $k_{\mathrm{L}} \mathrm{a} / \epsilon=0.5 \mathrm{~s}^{-1}$ in the "churn/turbulent regime" in a bubble column without trays. The difference between the ratio reported and that found in this study is due to the different flow regimes, as we worked exclusively in the bubble regime with a bubble size smaller than $4 \mathrm{~mm}$.

\section{Reactor Design Parameter}

The major design parameters for structured catalytic beds in a bubble column staged with fibrous layers are the thread diameter $D$, the width between the threads $\mathrm{w}$, and the distance between the fabrics $\mathrm{b}$.

Increasing the thread diameter $\mathrm{D}$ increases the length of diffusion for the reactants from the solution to the catalyst surface, which might influence the global reaction kinetics. The hydrodynamic properties are not significantly influenced by the thread diameter $\mathrm{D}$.

Increasing the width $w$ between the threads decreases the pressure drop $\Delta \mathrm{p}_{\mathrm{f}}{ }^{7}$ but al so decreases the $\mathrm{k}_{\mathrm{L}}$ a value (for low $u_{g 0}$ ). In technical applications with gas velocities higher than $15 \mathrm{~cm} / \mathrm{s}$, only the pressure drop $\Delta \mathrm{p}_{\mathrm{f}}$ has to be considered as a design parameter, because the influence of the layer structure on the $k_{L} a$ value is of minor importance. 
The degree of liquid-phase saturation by the gas is a function of the distance between the fabric layers $b$.

\section{Conclusions}

The tank-in-series model was found to describe accurately the residence time distribution of a bubble column staged with fibrous layers. For a dimensionless fabric distance $b / I D<1$, which will be the case in all technical applications, perfect mixing occurs between the fabric layers, and no liquid backflow between neighboring stages occurs.

The gas-liquid mass transfer coefficient $\mathrm{k}_{\mathrm{L}}$ a was found to depend on the superficial gas and liquid velocities, in contrast to conventional bubble columns, for which the liquid flow shows only a negligible effect on the mass transfer. The $\mathrm{k}_{\mathrm{L}} \mathrm{a}$ values in the present study are 10 times higher than those for an empty bubble column without any packing.

The main geometrical design parameters of the structured catalytic beds are the distance between the threads $w$ and the distance between the fibrous layers b.

\section{Symbols Used}

$\mathrm{a}=$ gas-liquid interfacial area per unit void $\left(\mathrm{m}^{2} / \mathrm{m}^{3}\right)$

$A_{0}=$ open area of the fibrous layers

$\mathrm{b}=$ distance between the fabric layers $(\mathrm{mm})$

$C(t)=$ response signal (dimensionless concentration $c / c_{0}$ )

$\mathrm{d}=$ filament diameter $(\mathrm{mm})$

$\mathrm{D}=$ thread diameter $(\mathrm{mm})$

$E(t)=$ age distribution $\left(\mathrm{s}^{-1}\right)$

$E F G=$ E-type glass fiber

$I D=$ inner diameter of the column $(\mathrm{mm})$

$\mathrm{k}_{\mathrm{L}} \mathrm{a}=$ volumetric gas-liquid mass transfer coefficient $\left(\mathrm{s}^{-1}\right)$

$\mathrm{N}=$ number of perfectly mixed tanks

$\Delta \mathrm{p}_{\mathrm{f}}=$ frictional pressure drop ( $\mathrm{Pa} /$ fibrous layer)

$\mathrm{u}_{\mathrm{g} 0}=$ superficial gas velocity $(\mathrm{cm} / \mathrm{s})$

$\mathrm{u}_{10}=$ superficial liquid velocity $(\mathrm{cm} / \mathrm{s})$

$\mathrm{w}=$ distance between the threads, width $(\mathrm{mm})$

$\mathrm{Re}=$ Reynolds number (with superficial velocity)

RTD $=$ residence time distribution

$\mathrm{S}=$ number of stages

$\overline{\mathrm{t}}=$ mean residence time $(\mathrm{s})$

$\mathrm{t}=$ time $(\mathrm{s})$

Subscripts

exp $=$ experimentally determined

calc $=$ calculated value

equ $=$ interfacial equilibrium concentration

in = input

out $=$ output

Greek Symbols

$\beta_{1}=$ liquid holdup

$\epsilon=$ gas holdup

$\rho_{l}=$ liquid density $\left(\mathrm{kg} / \mathrm{m}^{3}\right)$

$\sigma^{2}=$ variance of the residence time distribution $\left(\mathrm{s}^{2}\right)$

$\sigma_{\theta}^{2}=$ dimensionless variance of the residence time distribution

\section{Acknowledgment}

The financial support provided for this work by the Swiss National Foundation and the Max-Buchner Forschungsstiftung is gratefully acknowledged. The authors also thank Dipl. Ing. Dagmar Wegricht for the RTD measurements.

\section{Literature Cited}

(1) Shah, Y. T.; Kelkar, B. G.; Godbole, S. P.; Deckwer, W.-D. Design Parameter Estimations for Bubble Column Reactors. AIChE J . 1982, 28, 353.

(2) Deckwer, W-D. BubbleColumn Reactors; Wiley: New York, 1992.

(3) Hofmann, H. Packed up-flow bubble columns. Chem. Ing. Technol. 1982, 54, 865.

(4) Yang, Y. B.; Devanathan, N.; Duduković, M. P. Liquid backmixing in bubble columns via computer automated radioactive particle tracking (CARPT). Exp. Fluids 1993, 16, 1.

(5) Kiwi-Minsker, L.; Yuranov, I.; Höller, V.; Renken, A. Supported glass fiber catalysts for novel multi-phase reactor design. Chem. Eng. Sci. 1999, 54, 4785.

(6) Höller, V.; Wegricht D.; Yuranov, I.; Kiwi-Minsker, L.; Renken, A. Three Phase Nitrobenzene Hydrogenation over Supported Glass Fiber Catalysts: Reaction Kinetics Study. Chem. Eng. Technol. 2000, 23, 251.

(7) Höller, V.; Wegricht, D.; Kiwi-Minsker, L.; Renken, A. Fibrous structured catalytic beds for three-phase reaction engineering: Hydrodynamics study in staged bubble columns. Catal. Today 2000, 60, 51.

(8) Chen, B. H.; Yang, N. S. Characteristics of a Cocurrent Multistage Bubble Column. Ind. Eng. Chem. Res. 1989, 28, 1405.

(9) Chen, B. H.; Liu, C. H. Pressure Drop and Mass Transfer Coefficients in Concurrent Screen Plate Bubble Column. Chem. Eng. Commun. 1991, 100, 113.

(10) van Gelder, K. B.; Westerterp, K. R. Residence Time Distribution and Hold-up in a Cocurrent Upflow Packed Bed Reactor at Elevated Pressure. Chem. Eng. Technol. 1990, 13, 27.

(11) Briens, C. L.; Margaritis A.; Wild, G. A New Stochastic Model and Measurement Errors in Residence Time Distributions of Multiphase Reactors. Chem. Eng. Sci. 1995, 2, 279.

(12) Savitzky, A.; Goly, M.J. E. Smoothing and Differentiation of Data by Simplified Least Squares Procedures. Anal. Chem. 1964, 36, 1627.

(13) Levenspiel O. Chemical Reaction Enginering; Wiley: New York, 1999.

(14) Wegricht, D. Catalyst Development and Experimental Study of Three-Phase Hydrogenation Performed over a Structured Catalytic Bed. Master's Thesis, EPF Lausanne, Lausanne, Switzerland, 1999.

(15) Blass, E.; Cornelius, W. The Residence Time Distribution of Solid and Liquid in Multistage Bubble Columns in the Cocurrent Flow of Gas, Liquid and Suspended Solid. Int. J . MultiphaseF low $1977,3,459$.

(16) Blass, E.; Koch, K.-H. Strömungstechnische Untersuchungen an einem Blasensäulen-K askadenreaktor bei Gleichstrom von Gas und Flüssigkeit. Chem. Ing. Technol. 1972, 44, 913.

(17) Blass, E.; Cornelius, W. Betriebsverhalten von Blasensäulen-Kaskadenreaktoren. Chem. Ing. Technol. 1973, 45, 236.

(18) Nishikawa, M.; Shiino, K.; Kayama, T.; Nishioka, S.; Hashimoto, K. Gas Absorption in a Multi-Stage Gas-Liquid Spouted Vessel. J . Chem. Eng. J pn. 1985, 18, 496.

(19) Yang, N. S.; Shen, Z. W.; Chen, B. H.; McMillan, A. F. Pressure Drop, Gas Holdup and Interfacial Area for Gas-Liquid Contact in Karr Column. Ind. Chem. Process Des. Dev. 1986, 25, 660.

(20) Letztel, H. M.; Schouten, J . C.; Krishna, R.; van den Bleek, D. M. Gas holdup and mass transfer in bubble column reactors operated at elevated pressure. Chem. Eng. Sci. 1999, 54, 2237.

(21) Letzel, M.; Stankiewicz, A. Gas hold-up and mass transfer in gas-lift reactors operated at el evated pressures. Chem. Eng. Sci. 1999, 54, 5153.

(22) Vermeer, D. J .; Krishna, R. Hydrodynamics and Mass Transfer in Bubble Columns Operating in the Churn-Turbulent Regime. Ind. Eng. Chem. Process Des. Dev. 1981, 20, 475.

Received for review August 2, 2000 Accepted J anuary 7, 2001

IE000719F 